\title{
The European Respiratory Review: meeting expectations of respiratory physicians through diversity and quality
}

\author{
Vincent Cottin ${ }^{1,2}$
}

Affiliations: ${ }^{1}$ Hospices Civils de Lyon, Hôpital Louis Pradel, Service de pneumologie - Centre de référence national des maladies pulmonaires rares, Lyon, and ${ }^{2}$ Université de Lyon, Université Claude Bernard Lyon 1, INRA, UMR754 INRA-Vetagrosup EPHE IFR 128, Lyon, France.

Correspondence: V. Cottin, Hôpital Louis Pradel, Claude Bernard Lyon 1 University, 28 Avenue du Doyen Lepine, 69677 Lyon, France. E-mail: vincent.cottinachu-lyon.fr

○

@ERSpublications

$E R R$ welcomes increased diversity in both content format and topic including thematic and clinical year in review series http://ow.ly/sS8Ra

The European Respiratory Review (ERR) is the review journal of the European Respiratory Society (ERS) and sister journal of the European Respiratory Journal [1,2], which is the flagship journal the ERS [1]. A year ago, in an editorial as incoming ERR Chief Editor, I stated that the ERR was mature, expanding and meeting new challenges [3]. Indeed, readers may have already witnessed that the ERR is building on its success and growing, and including more and more high-quality content.

With the outstanding combined effort of authors, the ERS Publications Office, the ERS Publication Committee and the dedicated international editorial board, the ERR is successfully aiming at publishing the best review content in respiratory medicine. Because submission to the ERR is free and because all ERR articles are free to access, the $E R R$ contributes to the rapid dissemination of knowledge in respiratory medicine. This is illustrated by the ever increasing number of visits to the ERR website (http://err. ersjournals.com) and of the number of downloaded ERR articles worldwide [4], with 231636 visits and 510741 downloads in 2013. Importantly, the growing role of the ERR in the respiratory field is also exemplified by the increasing number of ERR articles that are being cited in articles in several international journals.

During 2013, the ERR has welcomed an increased diversity in both the format and the topics of content. In addition to publishing state-of-the-art reviews (updates), focused review articles, reports of high-quality scientific meetings, supporting documents of ERS task forces, sponsored review articles, editorials, letters to the editor and correspondence, the ERR now publishes thematic review series and Clinical year in review articles. The publication of cutting edge mini-reviews [5-9], case-based reviews [10] and images in respiratory medicine [11] has also been initiated, and spontaneous submissions are particularly welcome.

In 2013, two new series were introduced in the ERR covering "Topics in thoracic oncology" [12] and "Pulmonary rehabilitation" [13], and a new series on "Acute respiratory distress syndrome" will be launched in the June 2014 issue. Although not explicitly identified as part of a series, three outstanding short articles have further reviewed the common features between cancer and conditions generally considered as non-neoplastic (pulmonary arterial hypertension, lymphangioleiomyomatosis and idiopathic pulmonary fibrosis, $[8,9,14]$, with many learning points for both clinicians and scientists.

Received: Jan 202014 | Accepted: Jan 202014

Conflict of interest: None declared.

Provenance: Submitted article, peer reviewed

Copyright OERS 2014. ERR articles are open access and distributed under the terms of the Creative Commons Attribution Non-Commercial Licence 3.0. 
Clinical year in review articles are written, upon invitation, by respected speakers at the eponymous symposium of the ERS Congress, and focus on the most recent advances in clinical medicine. Four Clinical year in review articles were published in the March 2013 issue of the ERR [15-18] following the 2012 ERS Congress. In this issue of the ERR, four Clinical year in review articles [19-22] are published based on presentations from the 2013 ERS Congress in Barcelona, Spain, summarising the most important studies published in the 12 months prior to the ERS Congress.

I strongly believe that the current and future issues of the ERR will significantly contribute to the dissemination of up-to-date knowledge in various areas of respiratory medicine. If, as I am sure you do, you enjoy reading the ERR as much as the editorial board and I do, then tell your colleagues and students about the ERR!

\section{References}

Dinh-Xuan AT, Brusasco V, Wedzicha JA, et al. ERS publications: the flagship and the fleet. Eur Respir J 2012; 40: 535-537.

Humbert M. The ambition of the European Respiratory Journal: chapter 2. Eur Respir J 2014; 43: 1-2.

Cottin V. The European Respiratory Review: mature, expanding and targeting new challenges. Eur Respir Rev 2013; 22: $1-2$

Humbert M. You say goodbye, and I say hello!. Eur Respir Rev 2012; 21: 265-266.

5 Maharaj S, Shimbori C, Kolb M. Fibrocytes in pulmonary fibrosis: a brief synopsis. Eur Respir Rev 2013; 22: 552-557.

6 Molyneaux PL, Maher TM. The role of infection in the pathogenesis of idiopathic pulmonary fibrosis. Eur Respir Rev 2013; 22: 376-381.

Horsburgh Jr CR. Tuberculosis. Eur Respir Rev 2014; 23: 36-39.

Guignabert C, Tu L, Le Hiress M, et al. Pathogenesis of pulmonary arterial hypertension: lessons from lung cancer. Eur Respir Rev 2013; 22: 543-551.

9 El-Chemaly S, Henske EP. Towards personalised therapy for lymphangioleiomyomatosis: lessons from cancer. Eur Respir Rev 2014; 23: 30-35.

10 Dimopoulos K. Eisenmenger syndrome in an adult patient with a large ductus arterious. Eur Respir Rev 2013; 22: $558-564$.

11 Yatera K, Kawanami T, Ishimoto $\mathrm{H}$, et al. Progressive metastatic pulmonary calcification after successful renal transplantation. Eur Respir Rev 2013; 22: 98-99.

12 Girard N, Zalcman G. Topics in thoracic oncology: from surgical resection to molecular discussion. Eur Respir Rev 2013; 22: 101-102.

13 Gloeckl R, Marinov B, Pitta F. Practical recommendations for exercise training in patients with COPD. Eur Respir Rev 2013; 22: 178-186.

Vancheri C. Common pathways in idiopathic pulmonary fibrosis and cancer. Eur Respir Rev 2013; 22: 265-272.

Peacock A. Pulmonary hypertension. Eur Respir Rev 2013; 22: 20-25.

Cottin V. Interstitial lung disease. Eur Respir Rev 2013; 22: 26-32.

Sculier J-P. Nonsmall cell lung cancer. Eur Respir Rev 2013; 22: 33-36.

Tonnesen P. Smoking cessation and COPD. Eur Respir Rev 2013; 22: 37-43.

Antoniou KM, Margaritopoulos GA, Tomassetti S, et al. Interstitial lung disease. Eur Respir Rev 2014; 23: 40-54. Spruit M. Pulmonary rehabilitation. Eur Respir Rev 2014; 23: 55-63.

Murphy VE, Schatz M. Asthma in pregnancy: a hit for two. Eur Respir Rev 2014; 23: 64-68.

Sculier J-P, Meert A-P, Berghmans T. Updates in oncology. Eur Respir Rev 2014; 23: 69-78. 